\title{
Numerical crashworthiness analysis of an offshore wind turbine monopile impacted by a ship
}

\author{
A. Bela, L. Buldgen \& Ph. Rigo \\ University of Liège, ANAST, Liège, Belgium \\ H. Le Sourne \\ GeM Institute, Nantes, France
}

\begin{abstract}
The consequences of collision events can range from minor structural damages of the supporting structure to complete collapse of the wind turbine, which may lead to disruptions of the electricity production and, at worst, to sinking of the striking ship with probability of loss of human lives or/ and pollution. For all these reasons, a collision risk analysis becomes mandatory at the pre-design stage in order to identify the collision scenarios having the greatest probabilities of occurrence, to estimate the consequences of collision events and to ensure safe operations through the wind farm service life. The goal of this paper is to outline the behavior of the monopile foundations during ship collision by performing non-linear finite element simulations. Many collision scenarios are analyzed in order to study the sensitivity of the monopile to various parameters like impact striking ship velocity, nacelle mass, wind direction, soil stiffness, vertical location of the impact point, wind orientation ... The internal energy dissipated by deformation of the monopile, the crushing force and the indentation of the crushed area are compared for different situations, as well as the overall displacements of the supporting structure.
\end{abstract}

\section{INTRODUCTION}

\subsection{Offshore wind turbines}

The wind energy sector is in full process of development and in a near future, many offshore wind farms will be built in the coastal area.

Offshore wind farms can be built in shallow water, but also in deeper water. Depending on the water depth, several support structures are available like gravity based structures, monopiles, jackets, tripods and floating structures. This research focuses on the monopile structural support system.

The monopile structure is the most common support system for Offshore Wind Turbines (OWT) because of its simplicity in fabrication and installation. Nevertheless, it has the disadvantage of being too flexible in deep waters (DNV-OS-J101 2013). The possibility of deflection and vibration occurrence reduces the use of this foundation type to sites with maximum 25 meters water depth.

The monopile structure is composed of cylindrical steel tubes that are hammered into the seabed using hydraulic equipment. The connection with the tower is ensured through a transition piece which is also equipped with a mooring system for service vessels, a work platform and a ladder to access to the wind turbine.
As the offshore wind industry is expanding, the offshore wind farms will cover larger areas and will be located closer to the traffic lanes for commercial and passengers ships. As a consequence of this growth, the probability of ship collision events will increase. The consequences of collision events can range from minor structural damage to pollution and loss of human lives if the ship is sinking.

When a vessel impact an offshore wind turbine, there is first a local crushing of the impacted cylinder that occurs in a small area surrounding the impact point. This phenomenon has been investigated by Wierzbicki \& Suh (1988), Soares (1983), Amdahl (1982) or Ellinas (1984) amongst others. These authors derived analytical simplified formulae to evaluate the crushing force of an impacted cylinder. The quasi-static calculations were performed by using the energy theorems and were limited to the case of a point load. These developments were recently extended by Buldgen et al. (2014) to account for the influence of the shape of the striking bow.

However, when an offshore wind turbine is impacted, there is not only a local crushing, but an overall motion of the structure is also expected. Unfortunately, this topic is quite poorly reported in the literature. A study available on this subject is due to Pedersen (2013), who used an analytical 
approach to study the external dynamics of ship collisions against offshore structures.

Of course, these two behaviors do not necessarily occur sequentially but are in fact concomitant. This was studied by Amdahl \& Eberg (1993) for an offshore jacket. They pointed out that the crosssection reduction due to the localized crushing may have a large influence on the overall bending capacity of the structure. Neglecting this observation could therefore lead to a drastic overestimation of the collision resistance.

Apart from these analytical developments, some numerical studies are also available in the literature, but very few deal with monopiles. For example, Biehl \& Lehmann (2006) investigated the behavior of three support structures in collision scenarios. They analyzed the monopile, tripod and jacket foundation types by performing finite element analyses with the LS-DYNA software. More recently, Buldgen et al. (2014) investigated the ship impact on a jacket leg or brace by developing analytical formulations to calculate the crushing force as a function of penetration for a cylindrical element clamped at the extremities. These developments were validated by comparisons with numerical results that were also obtained with LS-DYNA.

\section{DAMAGE ANALYSIS}

The purpose of this research is to understand the collision mechanism, but also to see the influence on the behaviour of the collided structure of various parameters such as impact velocity, nacelle mass, wind, soil stiffness ...

To achieve this goal, a series of non-linear finite element simulations have been performed by using the software LS-DYNA. The finite element model contained both the structure of the wind turbine and the striking ship which is an Offshore Supply Vessel (OSV). Different configurations for the structure have been modelled in order to highlight the modifications in behavior induced by changing the boundary conditions or the loads. The numerical simulations performed are displacements controlled. In order to have a shorter computation time for the FEM simulations, the striking ship has not been modelled entirely. Indeed, as this research focuses on identifying the negative effects caused to the OWT structure in case of collision, the striking ship has been considered a rigid body (Le Sourne et al. 2014), which is a conservative assumption. However, in reality, the striking ship will also suffer some deformations as a result of the impact and the percentage of energy dissipated is shared between the OWT and the striking ship. The particularities of the finite element model of the wind turbine and also of the striking ship are presented in Table 1 and Table 2.
Table 1. FEM model particularities-OWT.

\begin{tabular}{lll}
\hline & \multicolumn{2}{l}{ Unit } \\
\cline { 2 - 3 } Characteristic & $\mathrm{m}$ & Tones \\
\hline Top diameter & 4 & - \\
Bottom diameter & 5 & - \\
Height & 115 & - \\
Wall thickness & 0.06 & - \\
Water depth & 25 & - \\
Nacelle mass & - & 350 \\
\hline
\end{tabular}

Table 2. FEM model particularities-OSV ship.

\begin{tabular}{lll}
\hline & \multicolumn{2}{l}{ Unit } \\
\cline { 2 - 3 } Characteristic & $\mathrm{m}$ & Tones \\
\hline Type & Bulbous & Bow \\
Length & 102.4 & - \\
Breadth & 23.23 & - \\
Depth & 25.89 & - \\
Draft & 4.12 & - \\
Displacement & - & 5000 \\
Water (added mass) & - & 250 \\
\hline
\end{tabular}

During a collision event, when a certain value of the tensile stress is reached, the structural element will fail. For the finite element model, failure was taken into account by using an erosive law. The thresholds failure strain is calculated according to Lehmann \& Peschmann (2002):

$\varepsilon_{f}=\varepsilon_{g}+\varepsilon_{e} \frac{t}{l_{e}}$

where $\varepsilon_{f}=$ failure strain, $\varepsilon_{g}=$ uniform strain, $\varepsilon_{e}=$ necking strain, $t=$ wall thickness, $l_{e}=$ element size.

\subsection{Influence of the impact velocity}

An important parameter for a collision event is the impact velocity and therefore, a series of head on collisions were analyzed. In the computation, three different initial velocities of the striking ship are considered: $2 \mathrm{~m} / \mathrm{s}, 3.5 \mathrm{~m} / \mathrm{s}$ and $5 \mathrm{~m} / \mathrm{s}$. Many offshore guidelines specify that the impact velocity for a standard collision scenario corresponding to supply vessels is $2 \mathrm{~m} / \mathrm{s}$ (Pedersen 2013). The impact velocity will decrease during collision due to reaction force between the ship and the OWT and at each time step a new value of the impact velocity will be calculated by LS-DYNA. 
In order to study the influence of the striking ship velocity on the behavior of the structure during collision, a series of FEM simulations are performed in which only the weight of the offshore wind turbine structure is taken into account, without the mass of the nacelle and rotor blades or any other loads. Regarding the boundary conditions, the soil stiffness is assumed to be infinite, so the lower part of the monopile is clamped.

At the beginning of the collision event, local crushing occurs in the impacted area. Once a certain value of the local indentation is reached, an overall bending of the structure also develops. The deformed shape of the structure during collision for the maximum values of the top displacements is shown in Figure 1.

The amount of energy dissipated through deformations occurred during collision is presented in Figure 2. The striking ship collides the wind turbine

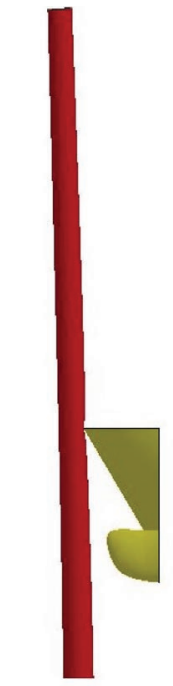

$\mathbf{v}=\mathbf{2} \mathrm{m} / \mathrm{s}$

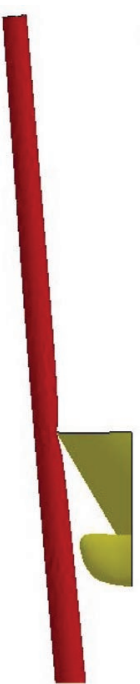

$\mathbf{v}=3.5 \mathrm{~m} / \mathrm{s}$

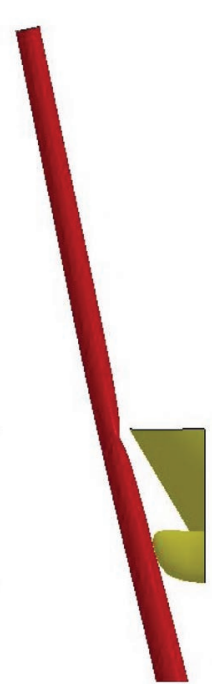

$\mathbf{v}=5 \mathrm{~m} / \mathrm{s}$
Figure 1. Deformed shape of the structure due to collision.

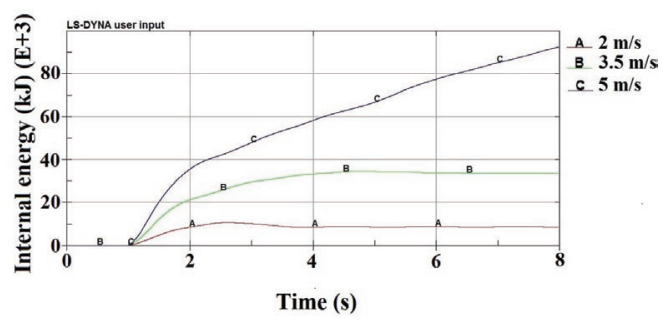

Figure 2. Internal energy for different impact velocities.
$1 \mathrm{~s}$ after the beginning of the simulation, because the gravity load is first imposed from 0 to $0.5 \mathrm{~s}$. In the case of an impact velocity of $2 \mathrm{~m} / \mathrm{s}$, when the collision occurs, the internal energy starts increasing and the maximum value is reached when the maximum deformations of the structure occurs. Looking at the internal energy associated with a $5 \mathrm{~m} / \mathrm{s}$ initial velocity, it can be seen that the structure will continue to deform until collapse, even after the contact between the ship and the structure is lost (Fig. 5). The deformations occurred after the collision force has decreased to 0 are due to the fact that the structure is pulled down by its own weight.

The cross section of the OWT structure is deformed during collision and the deformed shape is shown in Figure 3. It can be seen that for an impact velocity of $2 \mathrm{~m} / \mathrm{s}$, the deformations are not significant compared to the case of an impact velocity of $5 \mathrm{~m} / \mathrm{s}$, for which the value of the local denting reaches $1.7 \mathrm{~m}$ (Fig. 4). The reduction of the cross section of the OWT tower directly influences the overall bending capacity of the structure, as Amdahl \& Eberg (1993) already showed.

The crushing force time evolution is also influenced by the mass and the velocity of the striking ship. For an impact velocity of $2 \mathrm{~m} / \mathrm{s}$ only one contact occurs during collision in which all the kinetic energy is consumed, as depicted in Figure 5. For velocities of $3.5 \mathrm{~m} / \mathrm{s}$ and $5 \mathrm{~m} / \mathrm{s}$, three and two contacts respectively occur due to the dynamic nature of the impact force which causes an overall motion of the structure. When the collision starts, the crushing force increases until the structure starts moving faster than the striking ship and a loss of
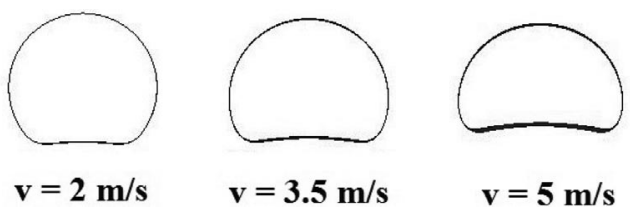

$\mathbf{v}=\mathbf{5} \mathbf{~ m} / \mathbf{s}$

Figure 3. Crushed area indentation.

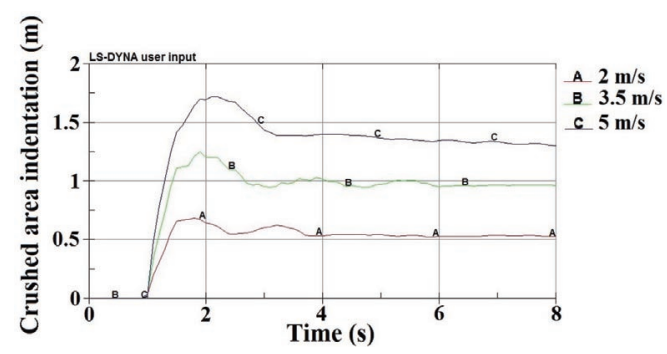

Figure 4. Crushed area indentation for different impact velocities. 


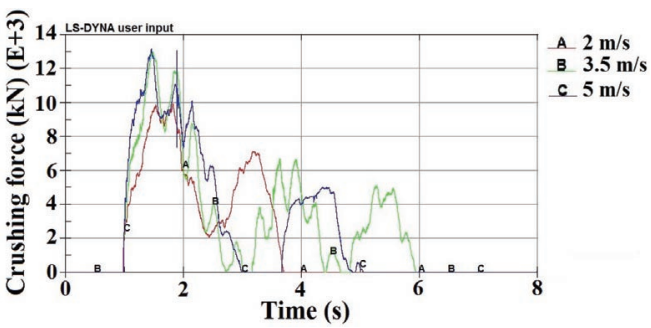

Figure 5. Crushing force for different impact velocities.

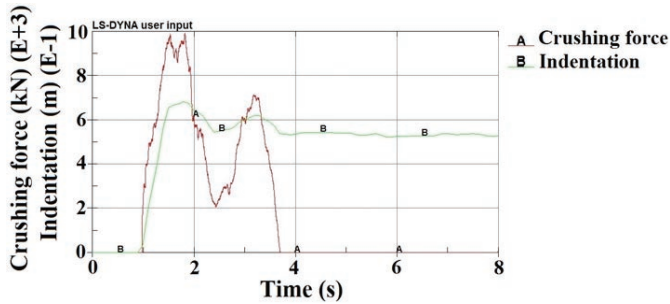

Figure 6. Crushing force and crushed area indentation for an impact velocity of $2 \mathrm{~m} / \mathrm{s}$.

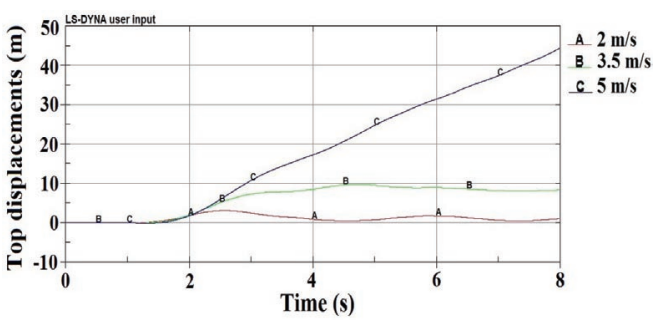

Figure 7. Top tower displacements for different impact velocities.

contact between the ship and the structure occurs. Therefore, multiple contacts occur until the all the kinetic energy is consumed.

The influence of the crushing force on the local denting in the crushed area is shown in Figure 6. In this graph it can be seen that when the value of the crushing force increases, the value of the local denting increases also. When the value of the crushing force decreases, an elastic relaxation occurs in the crushed area.

During collision, the top of the wind turbine experiences large displacements due to the overall deformation of the structure. For an impact velocity of $2 \mathrm{~m} / \mathrm{s}$, the maximum top displacements are less than $5 \mathrm{~m}$, while for an impact velocity of $3.5 \mathrm{~m} / \mathrm{s}$, the value of the top displacements reaches $10 \mathrm{~m}$ (Fig. 7). For a velocity of $5 \mathrm{~m} / \mathrm{s}$, the top displacements exceed $20 \mathrm{~m}$ and the structure collapses.

\subsection{Influence of the wall thickness}

Besides the influence of the impact velocity on the behavior of the structure, the influence of the wall thickness is also investigated. Three cases are analyzed with different values of the wall thickness: $0.05 \mathrm{~m}, 0.06 \mathrm{~m}$ and $0.07 \mathrm{~m}$. The velocity of the striking ship is considered $2 \mathrm{~m} / \mathrm{s}$ and the soil stiffness is assumed to be infinite.

The internal energy occurred due to deformations of the structure is depicted in Figure 8. This graph shows that the maximum value of the internal energy is not significantly different, but after the elastic relaxation of the structure, some divergences can be observed.

The structure with a wall thickness of $0.07 \mathrm{~m}$ is, as expected, more rigid compared to the one with $0.05 \mathrm{~m}$ and the deformations are smaller (Fig. 9).

The rigidity of the structure has obviously a large effect on the top displacements as shown in Figure 10.

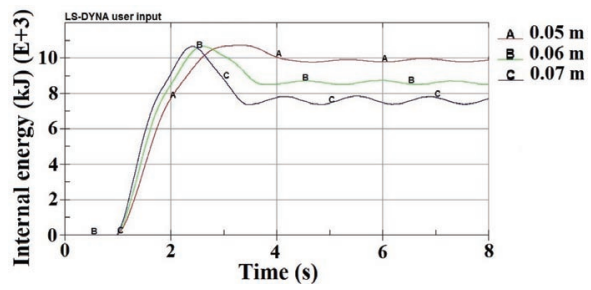

Figure 8. Internal energy for three different values of the wall thickness: $0.05 \mathrm{~m}, 0.06 \mathrm{~m}$ and $0.07 \mathrm{~m}$.

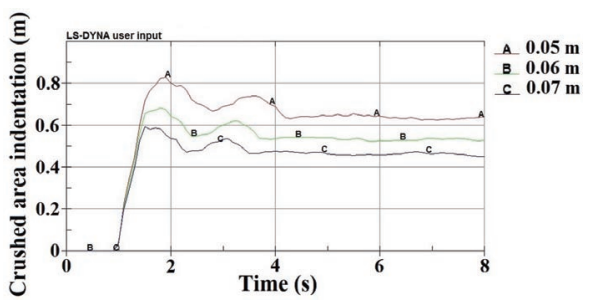

Figure 9. Crushed area indentation for three different values of the wall thickness: $0.05 \mathrm{~m}, 0.06 \mathrm{~m}$ and $0.07 \mathrm{~m}$.

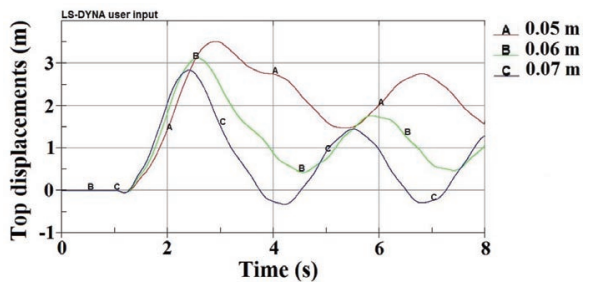

Figure 10. Top displacements for three different values of the wall thickness: $0.05 \mathrm{~m}, 0.06 \mathrm{~m}$ and $0.07 \mathrm{~m}$. 


\subsection{Influence of the gravity loads}

Besides the mass of the supporting structure of the OWT, another important parameter is the mass of the nacelle and rotor blades. The influence of the gravity loads and the mass inertia is studied for an impact velocity of $2 \mathrm{~m} / \mathrm{s}$ and infinite soil stiffness.

For this comparison, three cases were analyzed:

- No gravity: in the FEM analysis the gravity force is not included;

- Gravity: in the simulations the gravity force was taken into account;

- Added mass: in this case, besides the gravity force it was also taken into account the inertia effect of the mass of the nacelle and rotor blades $(350 \mathrm{t})$.

Figure 11 shows that the internal energy maximum values do not differ significantly when comparing the three different cases, while the inertia effect associated with nacelle and blades masses are visible through the elastic response of the monopile.

Accounting for the wind turbine inertia effect leads also to a different time evolution of the crushing force. As depicted in Figure 12, two successive impacts occur for the two first cases, while only one impact occurs when accounting for inertia effects.

As shown in Figure 13, the crushed area indentation for the case with no gravity and the one with the gravity included are quite similar. When the mass of the nacelle and rotor blades is included, it

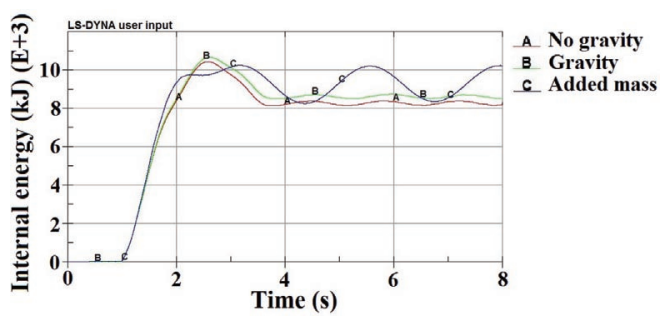

Figure 11. Internal energy for different load cases.

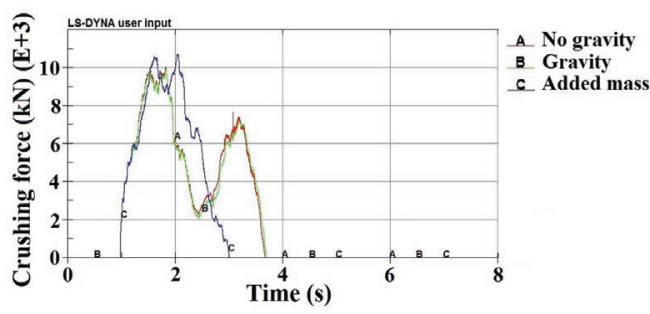

Figure 12. Crushing force for different load cases.

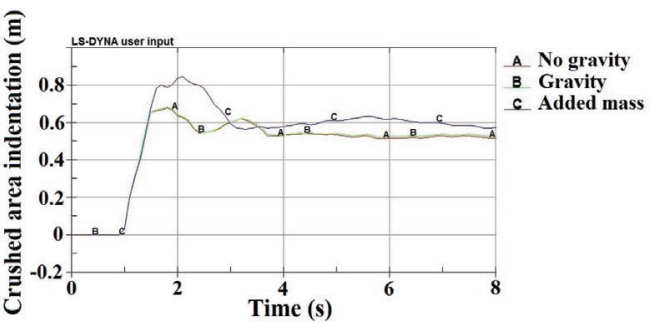

Figure 13. Crushed area indentation for different load cases.

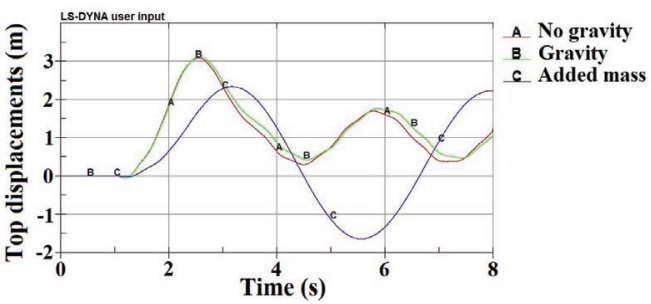

Figure 14. Top displacements for different load cases.

appears that a higher indentation occurs because in addition to the horizontal impact force, a vertical force, which corresponds to the nacelle (and rotor) weight, is acting on the structure.

The mass inertia also directly influences the structure top displacements. In Figure 14 is shown that for the 'Added mass' case, the top displacement occurs later because of the mass inertia and the structure oscillates around its equilibrium position.

\subsection{Influence of the wind}

Another important parameter for a collision analysis is the wind force and also the wind direction comparing to the striking ship direction.

For evaluating the influence of the wind on the behavior of the structure during collision, three cases are analyzed:

- Added mass (explained previously);

- Wind force (+): the impact and wind forces have the same direction;

- Wind force (-): the impact and wind forces have opposite directions.

A $2 \mathrm{~m} / \mathrm{s}$ impact velocity is considered and the soil stiffness is assumed to be infinite.

Figure 15 shows that the internal energy for the case 'Wind force ( + )' is much higher comparing to the 'Added mass' case, because the load applied by the wind on the wind turbine rotor increases the deformations. The maximum value of the internal 


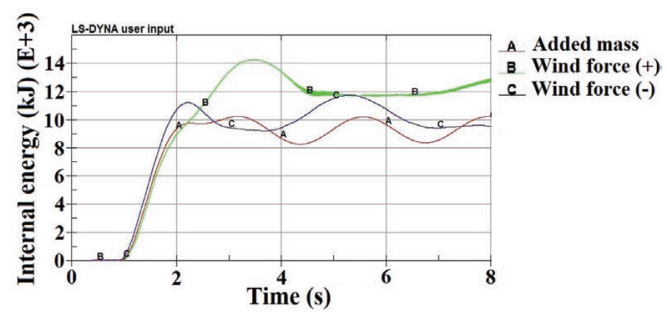

Figure 15. Internal energy for different wind directions.

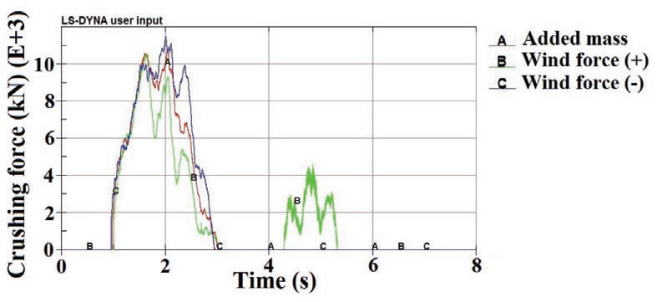

Figure 16. Crushing force for different wind directions.

energy for the case in which the wind and impact forces have opposite directions is lower than for the case 'Wind force (+)'.

The wind direction also influences the time evolution of the crushing forces: two impacts occur for the 'Wind force (+)' case and only one for 'Added mass' and 'Wind force (-)' cases (Fig. 16).

Regarding the crushed area indentation depicted in Figure 17, it is shown that the maximum indentation corresponds to the 'Wind force $(-)$ ' case, while the minimum value for the indentation corresponds to the 'Wind force (+)' one. This is due to wind direction comparing to the impact force one. For the case in which the wind force acts in the opposite direction as the impact force, the structure behaves like a clamped - simply supported beam subjected to a perpendicular concentrated force.

Consequently the top displacements of the tower are directly influenced by the wind force and also by the wind direction. Figure 18 shows that for the 'Added mass' case the structure oscillates around an equilibrium position that is very similar with the initial position of the structure, while for the 'Wind force (+)' and 'Wind force (-)' the top displacements are positive, respectively negative with respect to the impact force direction.

\subsection{Influence of the vertical position of the impact point (low tide/high tide)}

Depending on the water depth and on the characteristics of the striking ship, the impact location

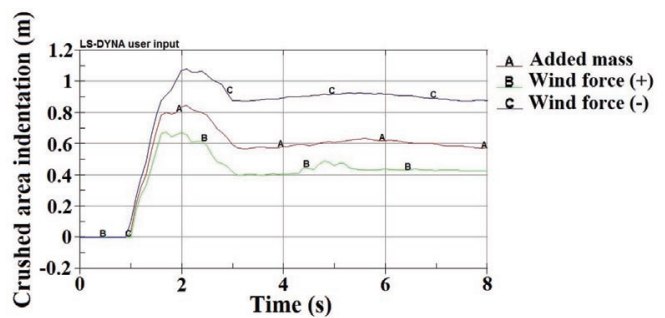

Figure 17. Crushed area indentation for different wind directions.

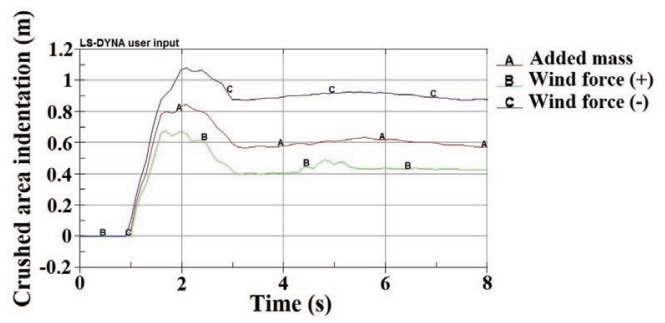

Figure 18. Top displacements for different wind directions.

can be different. A sensibility analysis of the impact point location was performed for three different water depths: $15 \mathrm{~m}, 20 \mathrm{~m}$ and $25 \mathrm{~m}$. The impact velocity is always equal to $2 \mathrm{~m} / \mathrm{s}$, the wind force has the same direction as the impact force and the soil stiffness is assumed to be infinite.

The values of the internal energy and of the crushed area indentation are similar for all the analyzed cases (Figs. 19 and 21).

Regarding the crushing force, for 15 and $20 \mathrm{~m}$ water depth only one contact occurs between the ship and the OWT, while two contacts occur for $25 \mathrm{~m}$ water depth. This is due to the increased lever arm from the base of the structure to the impact point (Fig. 20).

During collision, the structure suffers plastic deformations and a new equilibrium position will be found. In Figure 22, it is shown that for 15 and $20 \mathrm{~m}$ water depth, the new equilibrium position corresponding to the deformed shape is closer to the initial position than for the case with $25 \mathrm{~m}$ water depth.

\subsection{Influence of the soil stiffness}

In all above analyzed cases, the soil stiffness was assumed to be infinite, but in reality the soil will undergo some deformations. For this reason, a sensibility analysis is performed in order to investigate the influence of the soil stiffness on the behavior of the structure. 


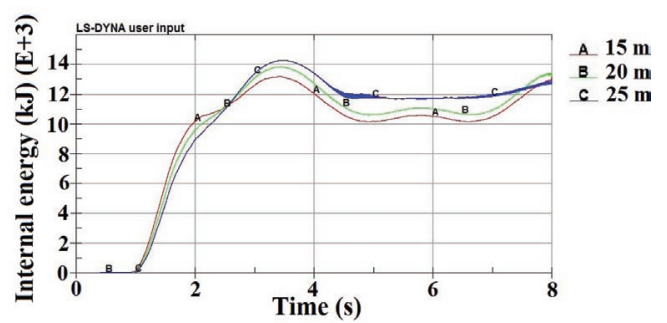

Figure 19. Internal energy for different water depths.

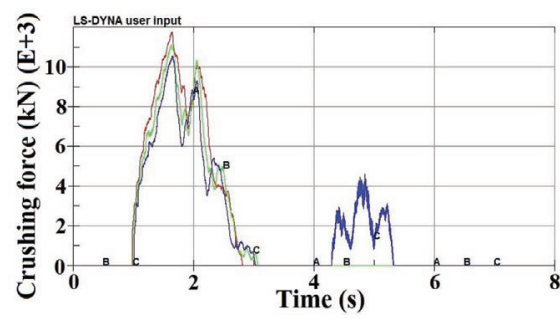

A $15 \mathrm{~m}$ B $20 \mathrm{~m}$

C. $25 \mathrm{~m}$

Figure 20. Crushing force for different water depths.

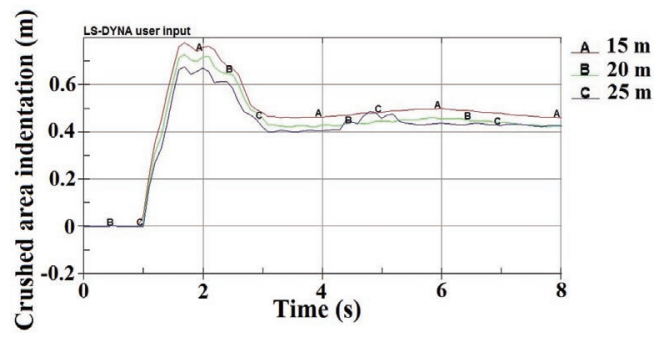

Figure 21. Crushed area indentation for different water depths.

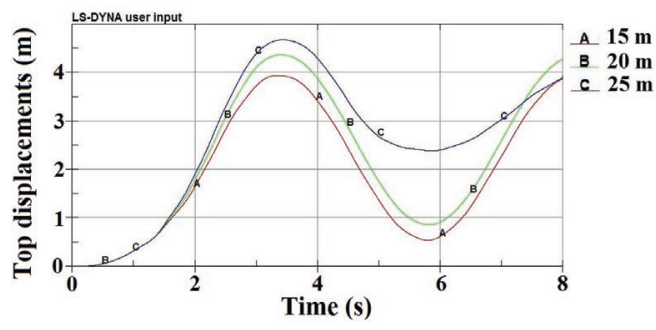

Figure 22. Top displacements for different water depths.

Two cases are analyzed:

- Wind force (+): the soil stiffness is assumed to be infinite;

- Wind force (+) SSI: in this case, the soil has a finite rigidity.
In the FEM model, the soil stiffness is modeled by using three translational and three rotational spring elements that corresponds to the central node of the bottom cross section. The central node is rigidly connected to the bottom edge of the monopile in order to transmit the loads to the soil (Fig. 23).

For the case in which the soil stiffness is considered to be infinite, when the collision occurs, the structure starts deforming in the crushed area and also at the bottom of the monopile, near the mudline. However, for the case in which spring elements model the soil rigidity, the bottom of the monopile rotates due to the elasticity of the soil. For a $2 \mathrm{~m} / \mathrm{s}$ impact velocity, no deformation occurs at the bottom of the monopile (Fig. 24).

For this reason, the deformations of the structure occurred in the case with infinite soil stiffness are higher than in the case with an elastic soil and as a consequence, the value of the internal energy is also higher (Fig. 25).

When the impact occurs, the structure starts deforming and for the case in which the soil stiffness is infinite, a loss of contact between the striking ship and the OWT occurs due to the overall motion of the structure which tends to be move faster than the striking ship until a second

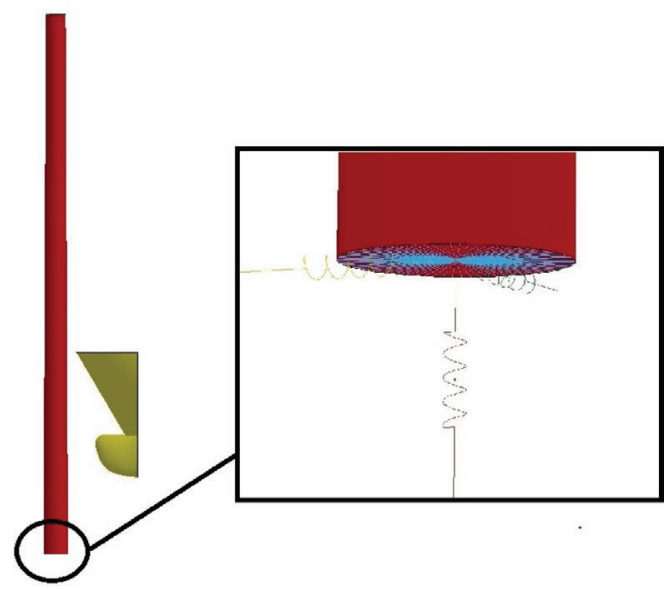

Figure 23. Soil-structure interaction: spring elements.

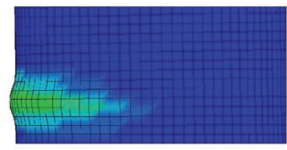

Wind force $(+)$

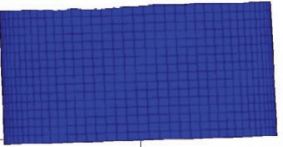

Wind force (+) SSI
Figure 24. Plastic strain at the bottom of the monopile. 


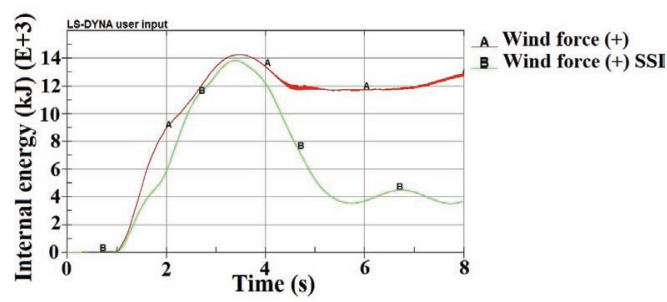

Figure 25. Internal energy for different boundary conditions.

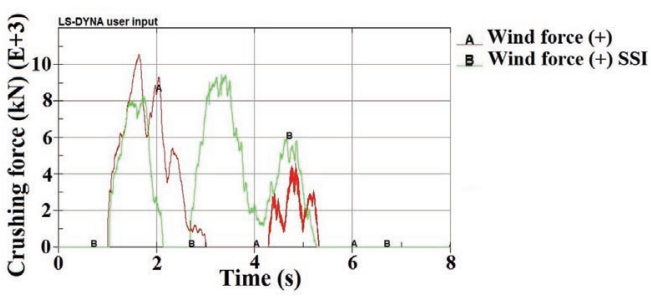

Figure 26. Crushing force for different boundary conditions.

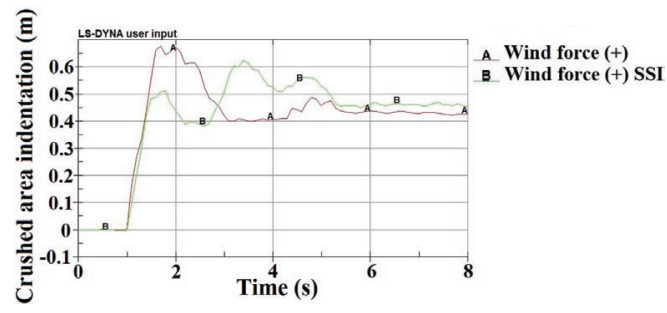

Figure 27. Crushed area indentation for different boundary conditions.

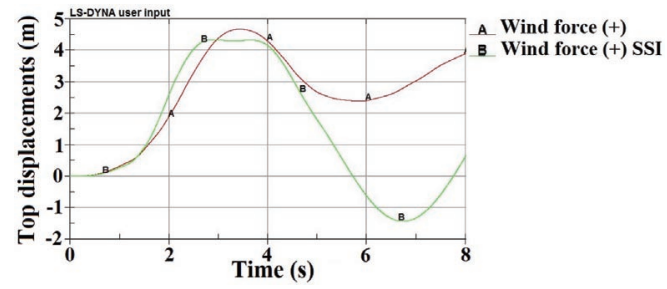

Figure 28. Top displacements for different boundary conditions.

impact occurs. Figure 26 shows that for an elastic soil, a loss of contact is also observed, but the second impact takes place earlier than in the previous case. The crushing force corresponding to the second impact is higher compared to the crushing force of the first impact.
By comparing the crushed area indentation for both studied cases, in Figure 27 is depicted that the maximum value of the crushed area indentation is higher for the case with infinite soil stiffness.

Due the elasticity of the soil, after collision the structure tends to go back to its initial position, but because of the deformations occurred during collision, the structure oscillates around the new equilibrium position corresponding to the deformed shape of the structure. Figure 28 shows that for infinite soil stiffness the permanent deformations of the structure are higher than for an elastic soil, and the deformed shape of the structure is much different in this case.

\section{CONCLUSIONS}

In this paper, a sensitivity analysis has been performed for a series of parameters like impact velocity, gravity loads, wind direction, soil stiffness ...

Table 3. Overview of the influence of different parameters.

\begin{tabular}{cc}
\hline Parameter & $\begin{array}{c}\text { Influence on the behavior of the structure } \\
\text { Impact }\end{array}$ \\
velocity & $\begin{array}{c}\text { The most influential parameter, whose } \\
\text { slight variation leads to significant } \\
\text { changes in the behavior of the structure } \\
\text { ranging from minor damage to collapse } \\
\text { The flexibility of the structure is directly } \\
\text { influenced by the wall thickness. The } \\
\text { thickness } \\
\text { greater the wall thickness the lower the } \\
\text { permanent plastic strains of the structure } \\
\text { This parameter influences the amount of } \\
\text { deformation in the crushed part of the } \\
\text { tower and the displacement at the top, } \\
\text { as well as its collapse behavior } \\
\text { The presence of the wind load in the same } \\
\text { direction as the impact force amplifies } \\
\text { the displacements at the top of the } \\
\text { tower, but in the crushed area the } \\
\text { deformations are smaller compared } \\
\text { to the case in which the wind force is } \\
\text { opposite to the impact force } \\
\text { The variation of the impact point position } \\
\text { for various tide conditions and ship } \\
\text { height is less significant with respect to } \\
\text { the height of the structure; therefore, } \\
\text { the response of the structure is similar, } \\
\text { excepting the case in which the water } \\
\text { depth is } 25 \text { m where a second impact } \\
\text { occurs corroborating with the tower top } \\
\text { displacements results } \\
\text { When considering SSI less energy is } \\
\text { dissipated through plastic deformations } \\
\text { and therefore, the internal energy is } \\
\text { lower and more energy is returned to the } \\
\text { system by means of oscillations }\end{array}$ \\
\hline & \\
&
\end{tabular}


A series of numerical simulations were conducted using the FE software LS-DYNA and the results obtained have been compared in order to determine which parameters influence the behavior of the structure during collision.

An overview of the influence of different parameters on the behavior of the structure is presented in Table 3.

This paper presents the work performed during the first step of the damage analysis for shipmonopile collision events. The results obtained by performing numerical simulations will serve as a basis for future analytical developments aiming to quickly estimate both the crushing resistance of the monopile and the external dynamics of the wind turbine.

\section{REFERENCES}

Amdahl J. (1982). Energy Absorption in Ship-Platform Impact, PhD Thesis, Norwegian Institute of Technologies. Trondheim.

Amdahl, J., \& Eberg, E. (1993). Ship collision with offshore structures. Proceedings of the 2nd European Conference on Structural Dynamics EURODYN,93. Norway Trondheim

Biehl, F., \& Lehmann, E. (2006). Collisions of ships with offshore wind turbines: Calculation and risk evaluation. Offshore Wind Energy 281-304. Springer Berlin Heidelberg.
Buldgen, L., Le Sourne, H., \& Pire, T. (2014). Extension of the super-elements method to the analysis of a jacket impacted by a ship. Marine Structures, 38, 44-71.

DNV-OS-J101. (2013). Design of Offshore Wind Turbine Structures, Section 1.

Ellinas, C.P. (1984). Ultimate strength of damaged tubular bracing members. Journal of Structural Engineering, 110(2), 245-259.

Lehmann, E., \& Peschmann, J. (2002). Energy absorption by the steel structure of ships in the event of collisions. Marine Structures, 15(4), 429-441.

Le Sourne H., Barrera A., Maliakel J.B. (2014). Numerical Crashworthiness Analysis of an Offshore Wind Turbine Jacket Impacted by a Ship. Submitted to the Journal of Marine Science and Technology.

Pedersen, P.T. (2013). Ship collisions against wind turbines, quays and bridge piers. Proceedings of the 6th International Conference on Collision and Grounding of Ships and Offshore Structures, ICCGS 2013. 273280 C R C Press LLC.

Soares, C.G., \& Søreide, T.H. (1983). Plastic analysis of laterally loaded circular tubes. Journal of Structural Engineering, 109(2), 451-467.

Wierzbicki, T., \& Suh, M.S. (1988). Indentation of tubes under combined loading. International Journal of Mechanical Sciences, 30(3), 229-248. 